\title{
A SPECIFIC PROCEDURE FOR SEISMIC DESIGN OF COLD-FORMED STEEL HOUSING
}

\author{
R. Landolfo ${ }^{1, *}$, L. Fiorino $^{2}$ and O. Iuorio ${ }^{3}$ \\ ${ }^{I}$ Full Professor, Department of Constructions and Mathematical Methods in Architecture, \\ Faculty of Architecture, University of Naples Federico II, Naples, Italy \\ ${ }^{2}$ Research Fellow, Department of Structural Engineering, University of Naples "Federico II", Naples, Italy \\ ${ }^{3}$ PhD, Department of Design, Rehabilitation and Control of Architectural Structures, \\ University of Chieti/Pescara “G. D'Annunzio", Pescara, Italy \\ *(Corresponding author: E-mail: landolfo@unina.it)
}

Received: 4 June 2008; Revised: 19 September 2008; Accepted: 21 October 2008

\begin{abstract}
In the last years, the seismic performance of cold formed steel (CFS) systems has been object of study by a large number of research teams. The main parameters influencing the system behaviour under horizontal loads have been defined and the possible mechanisms of collapse have been identified. Therefore, at the moment, the development of upgraded specifications and design tools that could be readily used by designer is a must. For these reasons, this paper aims to propose a seismic design procedure that allows the shear wall components to be defined in few steps. The procedure is based on the recognized assumption that the best performance of a CFS shear wall is achieved when the sheathing-to-stud fasteners failure is reached. Moreover, it accounts the results of previous studies that defined the relation between behaviour of shear wall and fastener spacing. Hence, by defining three nomographs, the proposed procedure allows the sheathing-to-stud fasteners and all the other shear wall components to be defined. The latter are determined in accordance with capacity design criteria. Finally, the applicability of the presented procedure is verified through a case study.
\end{abstract}

Keywords: Design nomographs, cold-formed steel, housing, linear dynamic analysis, nonlinear static analysis, seismic design, sheathing panels

\section{INTRODUCTION}

The growing demand of high performance housing is increasing the interest for cold-formed steel (CFS) structures. These structures are realized with a repetitive number of light gauge cold-rolled steel profiles, produced off-site in controlled environment and, then, assembled on-site with mechanical connections. These characteristics provide them lightness, rapid on-site erection, dimensional stability, high structural performance and considerable potential for recycling and reuse of all the materials. In particular, the spreading use of these constructions in countries as Japan shows the wide applicability of these systems also in seismic zones (Figure1). The global horizontal response of CFS structures under seismic actions basically depends on the shear response of CFS walls that are usually sheathed with metal sheets or panels (sandwich panels, wood-based or gypsum-based panels). Moreover, when the sheathing has adequate strength and stiffness and it is effectively connected with the frame, then the interaction between profiles, sheathing panels and sheathing-to-frame connections can be advantageously taken into account in the structural analysis. In this case, the definition of shear wall elements (studs, sheathing panels, sheathing-to-frame connections, and frame-to-foundation anchors), that constitute the main lateral resisting system in case of seismic actions, is a key point for the design. Currently, a relatively large database of experimental investigations carried out on different CFS wall assemblies subjected to in plane shear loading has been obtained by Gad et al. [1], Tian et al. [2], Branston et al. [3], Fulop and Dubina [4], Landolfo et al. [5], Langea and Naujoks [6], Serrette et al. [7]. As result, the main parameters influencing the shear behaviour of walls have been identified. As a consequence, some general guidelines for the design of sheathed CFS walls have been recognized, as the use of oversized chord studs and shear and hold-down anchors. Therefore, if CFS walls are designed 
following these basic guidelines, then a good lateral response, characterized by sheathing-to-frame connections collapse can be obtained. Nowadays, moving from these cardinal points, different design methodologies are available (UBC [8] and IBC [9] design tables), but the development of tools that could readily be used by designers should be improved. In an attempt to give a contribution on this topic, a specific seismic design procedure is presented hereafter. Finally, the applicability of the proposed designed procedure is investigated through a case study.
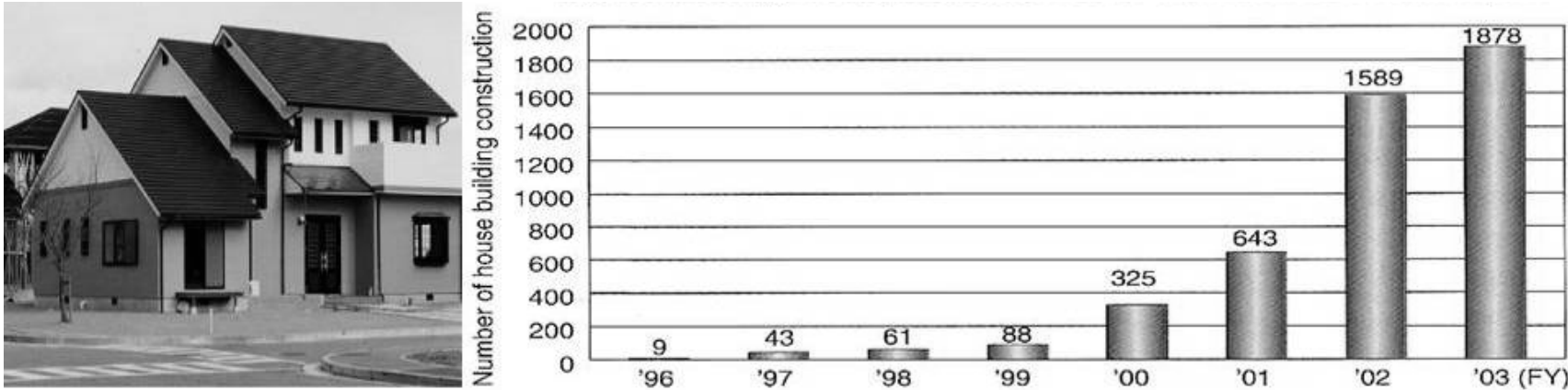

Figure 1. CFS Housing in Japan: Growing Construction in the Last Ten Years

\section{THE PROPOSED DESIGN PROCEDURE}

The proposed seismic design procedure refers to CFS walls sheathed with wood-based or gypsum-based panels, in which the wall components (Figure 2) are designed in such a way to promote the sheathing-to-frame fastener failure. The design procedure can be summarized in three consecutive phases (Figure 3):

1) definition of the wall geometry (wall height $h$, stud spacing $c$ ) and some parameters of the wall components: sheathing (type, thickness, orientation), frame (steel grade, stud size, with the exception of the thickness $t$, track size) sheathing-to-frame connections (type, interior spacing $p$, edge distance $e$ ), hold-down anchors (type) and shear anchors (type).

2) evaluation of the sheathing-to-frame fastener exterior spacing $s$;

3) evaluation of other design parameters (stud thickness $t$, hold-down anchor diameter $\phi$, shear anchor spacing $a$ ).

In this design procedure, the selection of the "assigned" design parameters (phase 1), usually derives from architectural and technological considerations and design for vertical loads. Therefore, no additional information are provided hereafter. Moreover, only the assessment of the sheathing-to-frame fasteners exterior spacing $(s)$ directly derives from seismic analysis results (phase 2), while the definition of stud thickness $(t)$, hold-down anchor diameter $(\phi)$, and shear anchor spacing $(a)$ is carried out on the basis of "capacity design" criteria (phase 3).

More details about the hypothesis and limit of applicability of this proposed procedure can be found in [10] 


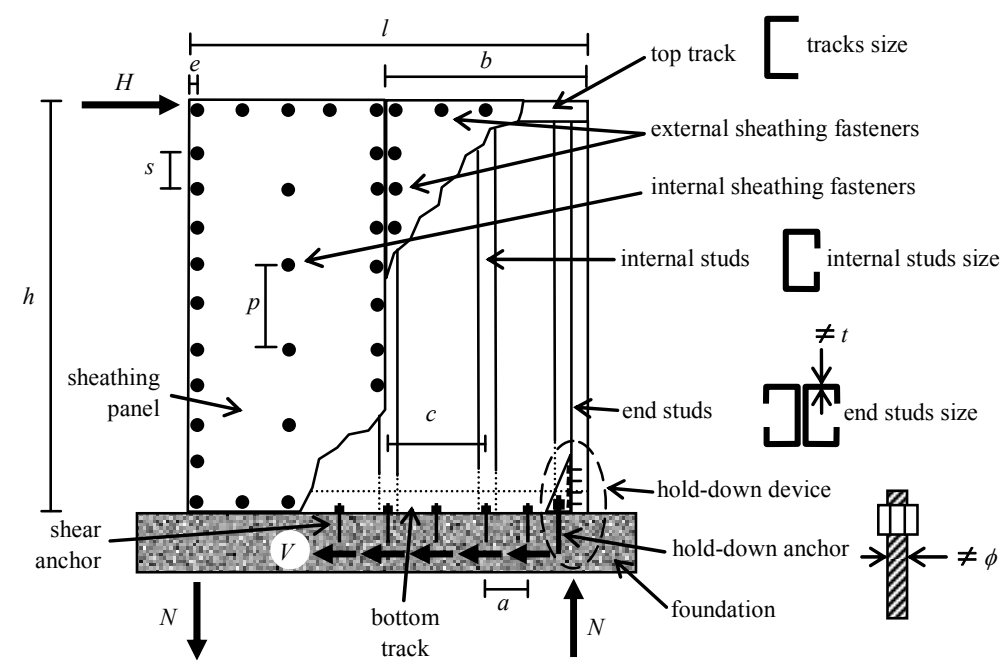

$N$ : axial force acting on the end stud / hold-down anchor, $V$ : shear force acting on a shear anchor

Figure 2. Geometry and Component of Typical Sheathed CFS Shear Wall

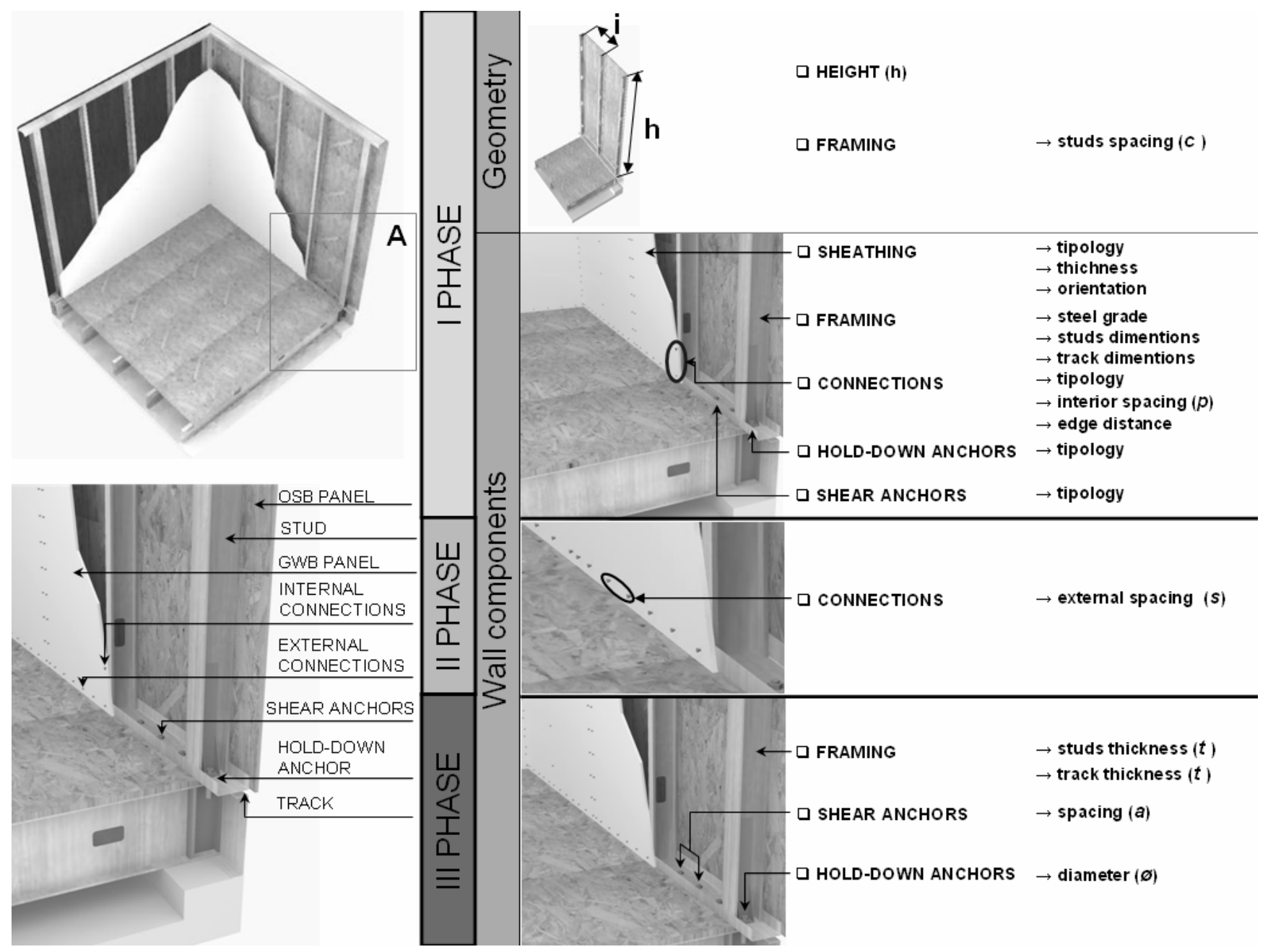

Figure 3. Proposed Design Procedure Schema 


\section{PHASE 2: EXTERIOR SPACING EVALUATION}

\subsection{Linear Dynamic Seismic Procedure}

When the linear dynamic (LD) procedure is selected for the seismic analysis, a force-based design approach is usually used, in which the inelastic behaviour and the structural overstrength are taken into account by the seismic force modification factors. In this case, the comparison between seismic capacity and demand, in terms of forces, shall satisfy the following equation:

$$
H_{C} \geq H_{D}
$$

where $H_{C}$ and $H_{D}$ are the seismic strength capacity and seismic action demand, respectively.

In particular, the seismic action $\left(H_{D}\right)$, which represents the horizontal in-plane force acting on the wall, can be evaluated through the following well known relationships:

$$
H_{D}=S_{a} \cdot \frac{w}{g} S_{a}=f_{S_{a} T}(T, \xi) T=2 \pi \sqrt{\frac{w / g}{K}}
$$

where: $S_{a}$ is the spectral acceleration; $f_{S a T}$ is the spectral acceleration function; $T$ is the structural period; $\xi$ is the viscous damping ratio; $w$ is the seismic weight; $g$ is the gravity acceleration; and $K$ is the wall shear stiffness, which can be expressed as a function of the sheathing fasteners exterior spacing $(s)$ :

$$
K=f_{K}(s)
$$

Also the seismic resistance $\left(H_{C}\right)$, which represents the wall shear strength, can be obtained as a function of $s$ :

$$
H_{C}=f_{H}(s)
$$

Therefore, for each value of exterior spacing $(s)$, if the functions $f_{S a T}, f_{K}$, and $f_{R}$ are known, then for fixed values of seismic weight $(w)$ and viscous damping ratio $(\xi)$, both seismic action $\left(H_{D}\right)$ and resistance $\left(H_{C}\right)$ can be calculated and compared by using Eq. (2) through (4) until Eq. (1) is satisfied. This design procedure can be represented graphically by means of the "LD" nomograph, as shown in Figure 4.

\subsection{Nonlinear Static Seismic Procedure}

When the seismic analysis is performed by means of the nonlinear static (NS) procedure, the inelastic behaviour and the structural overstrength are directly considered and the comparison between seismic capacity and demand can be achieved in terms of displacements (displacement-based approach):

$d_{C} \geq d_{D}$

where $d_{C}$ and $d_{D}$ are the seismic displacement capacity and seismic displacement demand, respectively. 


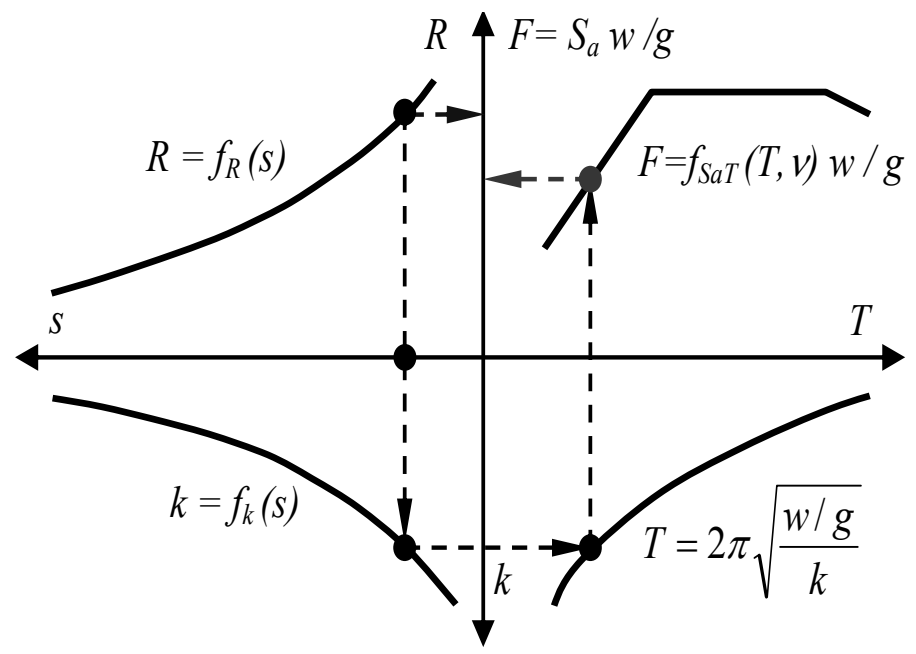

Figure 4. "LD” Nomographs

This comparison can readily be performed by means of the well known acceleration-displacement spectrum, in which the demand and capacity spectra are represented together. In particular, the demand spectrum can be obtained as follows:

$$
S_{a}=f_{\text {Sad }}(d, \xi)
$$

where $f_{\text {Sad }}$ is the spectral acceleration function, and $d$ is the generic displacement.

The capacity spectrum, instead, can be represented by an elastic-plastic curve, which is drawn by defining the yield $(Y)$ and ultimate $(U)$ limit points:

$$
Y\left(d_{y} ; \frac{H_{C}}{w} g\right), \quad U\left(d_{u} ; \frac{H_{C}}{w} g\right)
$$

where the yield displacement $\left(d_{y}\right)$ and ultimate displacement $\left(d_{u}\right)$ can be obtained as function of the exterior spacing $(s)$

$$
d_{y}=f_{y}(s)
$$

Therefore, for each value of exterior spacing $(s)$, if the functions $f_{\text {Sad }}, f_{H}, f_{y}$, and $f_{u}$ are known, then for fixed values of seismic weight $(w)$ and viscous damping ratio $(\xi)$, both seismic demand $\left(d_{D}\right)$ and capacity $\left(d_{C}\right)$ can be calculated and compared by using Eq. (6) through (8) until Eq. (5) be satisfied. This design procedure can be represented graphically by means of the "NS" nomograph shown in Figure 5. 


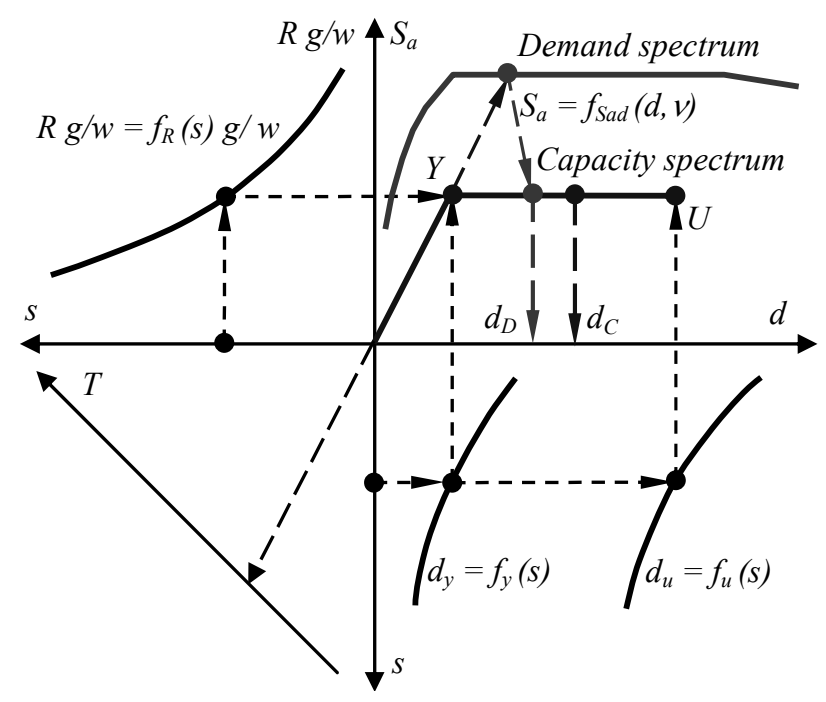

Figure 5. "NS" Nomograph

\section{PHASE 3: EVALUATION OF THE OTHER DESIGN PARAMETERS}

When the sheathing-to-frame fastener exterior spacing $(s)$ has been defined, then the evaluation of stud thickness $(t)$, hold-down anchor diameter $(\phi)$, and shear anchor spacing $(a)$ need to complete the wall design. The design procedure to define these last parameters can be represented graphically by means of an "OC" nomograph (Figure 6), in which the wall shear strength per wall unit length $\left(\bar{H}_{C}\right)$ corresponding to the resistance of sheathing fasteners $\left(\bar{H}_{C, f}\right)$, studs $\left(\bar{H}_{C, s}\right)$, hold-down anchors $\left(\bar{H}_{C, h a}\right)$ and shear anchors $\left(\bar{H}_{C, s a}\right)$ are represented together as function of the exterior spacing $(s)$. In particular, $\bar{H}_{C, f}$ can be obtained by knowing the function given in Eq. (4), while $\bar{H}_{C, s}, \bar{H}_{C, h a}$, and $\bar{H}_{C, s a}$ are calculated starting from the stud compression axial strength $\left(N_{s}\right)$, tension axial strength of hold-down anchor $\left(N_{h a}\right)$, and shear strength of the shear anchor $\left(V_{s a}\right)$ :

$$
\bar{H}_{C, s}=\frac{H_{C, s}}{l}=\frac{N_{s}}{h}, \quad \bar{H}_{C, h a}=\frac{H_{C, h a}}{l}=\frac{N_{h a}}{h}, \quad \bar{H}_{C, s a}=V_{s a}\left(\frac{1}{a}+\frac{1}{l}\right)
$$

where $l$ and $h$ are the wall length and height, respectively.

The unit wall strength corresponding to the resistance of sheathing fasteners $\left(\bar{H}_{C, f}\right)$ decreases when the exterior spacing $(s)$ increases, while $\bar{H}_{C, s}, \bar{H}_{C, h a}$, and $\bar{H}_{C, s a}$ are constant values. Hence, for a fixed value of exterior spacing $(s)$, the design parameters $(t, a$, and $\phi)$ can be calculated by using the "OC nomograph", in such way that the "capacity design" criteria are satisfied:

$$
\frac{\bar{H}_{C, s, k}}{\gamma_{o v, s}} \geq \bar{H}_{C, f, d} \quad \frac{\bar{H}_{C, h a, k}}{\gamma_{o v, h a}} \geq \bar{H}_{C, f, d} \quad \frac{\bar{H}_{C, s a, k}}{\gamma_{o v, s a}} \geq \bar{H}_{C, f, d}
$$

where: $\bar{H}_{C, s, k}, \bar{H}_{C, h a, k}$, and $\bar{H}_{C, s a, k}$ are the wall shear characteristic strengths per wall unit length corresponding to the resistances of studs, hold-down anchors and shear anchors, respectively. 
$\bar{H}_{C, f, d}$ is the wall shear design strength per wall unit length corresponding to the resistance of sheathing fasteners. Finally, $\gamma_{o v, s}, \gamma_{o v, h a}, \gamma_{o v, s a}$ are the overstrength factors of studs, hold-down anchors, and shear anchors, respectively.

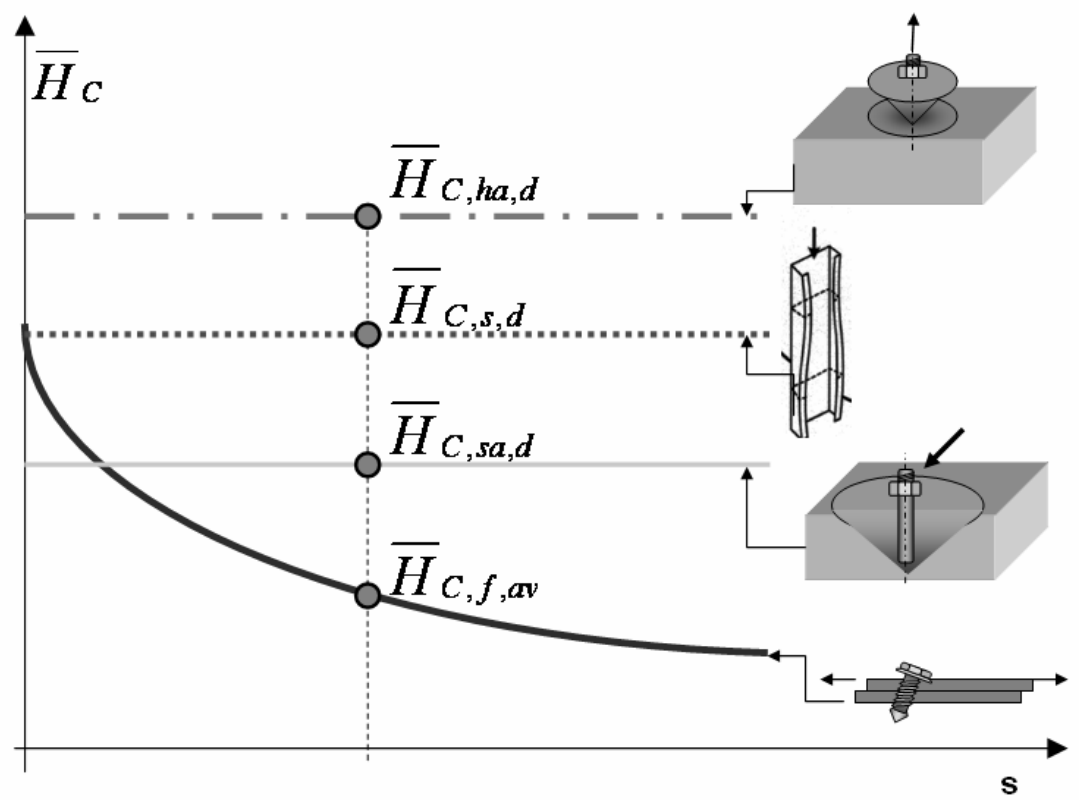

Figure 6. "OC" Nomograph

\section{DEFINITION OF STIFFNESS, STRENGTH, YIELDING AND ULTIMATE DISPLACEMENTS}

For the evaluation of the seismic response of this type of structures, according to the proposed design procedure, the relationships defining the wall shear response $\left(f_{k}, f_{H}, f_{y}\right.$, and $\left.f_{u}\right)$ as function of exterior spacing $(s)$ are required. In particular, in the case of LD seismic analysis, only wall stiffness $\left(f_{K}\right)$ and strength $\left(f_{H}\right)$ must be defined, while for the application of NS procedure, the definition of the elastic-plastic curve through the functions $f_{H}, f_{y}$, and $f_{u}$ usually requires the knowledge of the whole force $(H)$ - displacement $(d)$ response curve of the wall.

Different approaches can be used to perform an analysis devoted to obtain the functions $f_{K}, f_{H}, f_{y}$, and $f_{u}$; namely experimental (Serrette et al. [11]), numerical (Dolan [12], Dolan and Foschi [13], White and Dolan [14]) and analytical methodologies (Easley et al. [15], McCutchenon [16], Kaellsner and Lam [17], Hieta and Kesti [18]). In particular, analytical approaches used to analyze sheathed CFS shear walls generally allow only stiffness, strength and deflection $\left(f_{K}, f_{H}, f_{y}\right)$ to be predicted, without providing a reliable evaluation of the whole force - displacement response curve. To overcome this limitation, a specific analytical-numerical method has been developed by the authors allowing the prediction of the whole curve in terms of $f_{K}, f_{H}, f_{y}$ and $f_{u}$.

According to this methodology, the lateral displacement of a sheathed CFS shear wall can be obtained by adding four different deformation contributions (Figure 7):

$d=d_{f}+d_{s}+d_{b}+d_{a}$

where: $d_{f}$ represents the sheathing fasteners deformation, $d_{s}$ the sheathing panels shear deformation, $d_{b}$ the bending deformation, and $d_{a}$ the overturning deformation. 
If the local behaviour of sheathing fasteners governs the global lateral response of the wall (this is the usual condition), in the Eq. (11) the sheathing panels shear deformation, bending deformation and overturning deformation produce lateral displacements smaller than that due to sheathing fasteners deformation $\left(d_{s}<<d_{f}, d_{b}<<d_{f}, d_{a}<<d_{f}\right)$. In addition, $d_{s}, d_{b}$ and $d_{a}$ can be assumed as linear functions of the horizontal external force $(H)$, while the nonlinear lateral response of the wall is essentially the result of the inelastic behaviour of the sheathing fasteners $\left(d_{f}\right.$ is a nonlinear function of $H$ ). The model assumes that, at the beginning, the different deformation contributions can be independently evaluated and then they can be added.
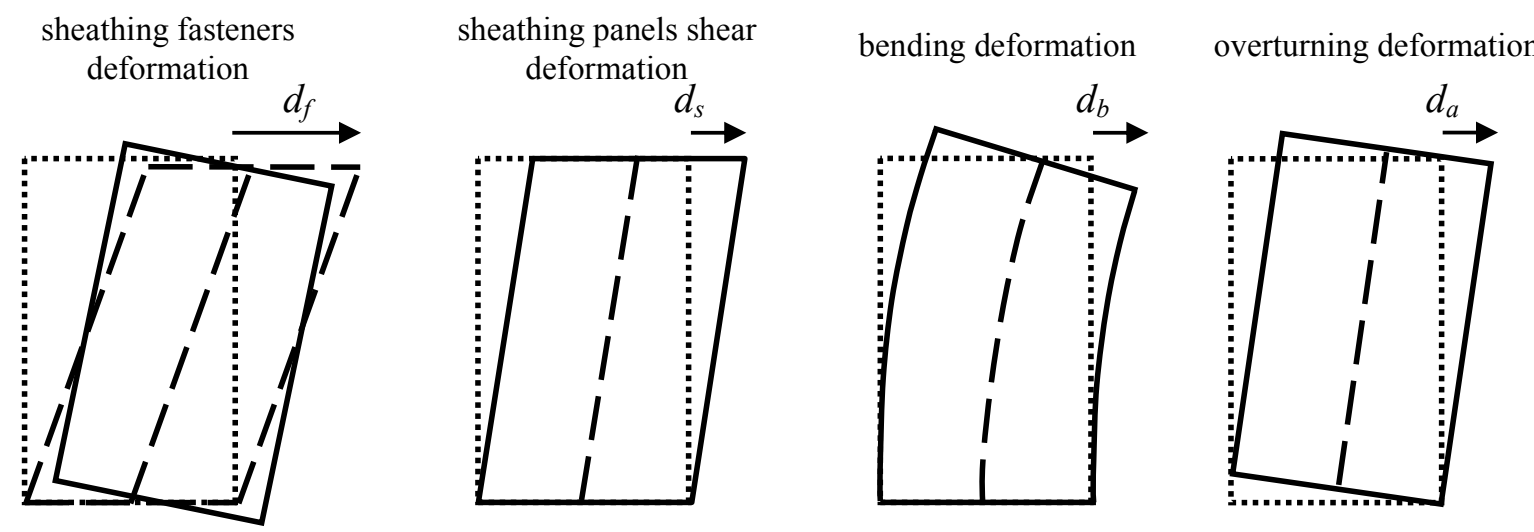

Figure 7. Deformation Component of a Sheathed CFS Shear Wall

For evaluating the lateral displacement $\left(d_{f}\right)$ due to the sheathing fasteners (frame-to-sheathing panel deformation), the following hypotheses are made: (a) the local failure of sheathing-to-frame connections governs the global collapse mode; (b) steel members are rigid and hinged to each other; (c) the frame deforms into a parallelogram and the relative frame-to-panel displacements are determined taking into account a rigid body rotation of panels; (d) the edges of the panel are free to rotate without interference from any other elements; (e) the wall is fully anchored; (f) relative displacements between the sheathing and frame are small compared with the panel size; (g) only shear deformation of sheathings is considered; (h) load-displacement curves of the sheathing-to-frame connections are schematized by using the relationship proposed by Richard and Abbott [19]. The assumed deformation of a sheathed cold-formed shear wall is shown in Figure 8.

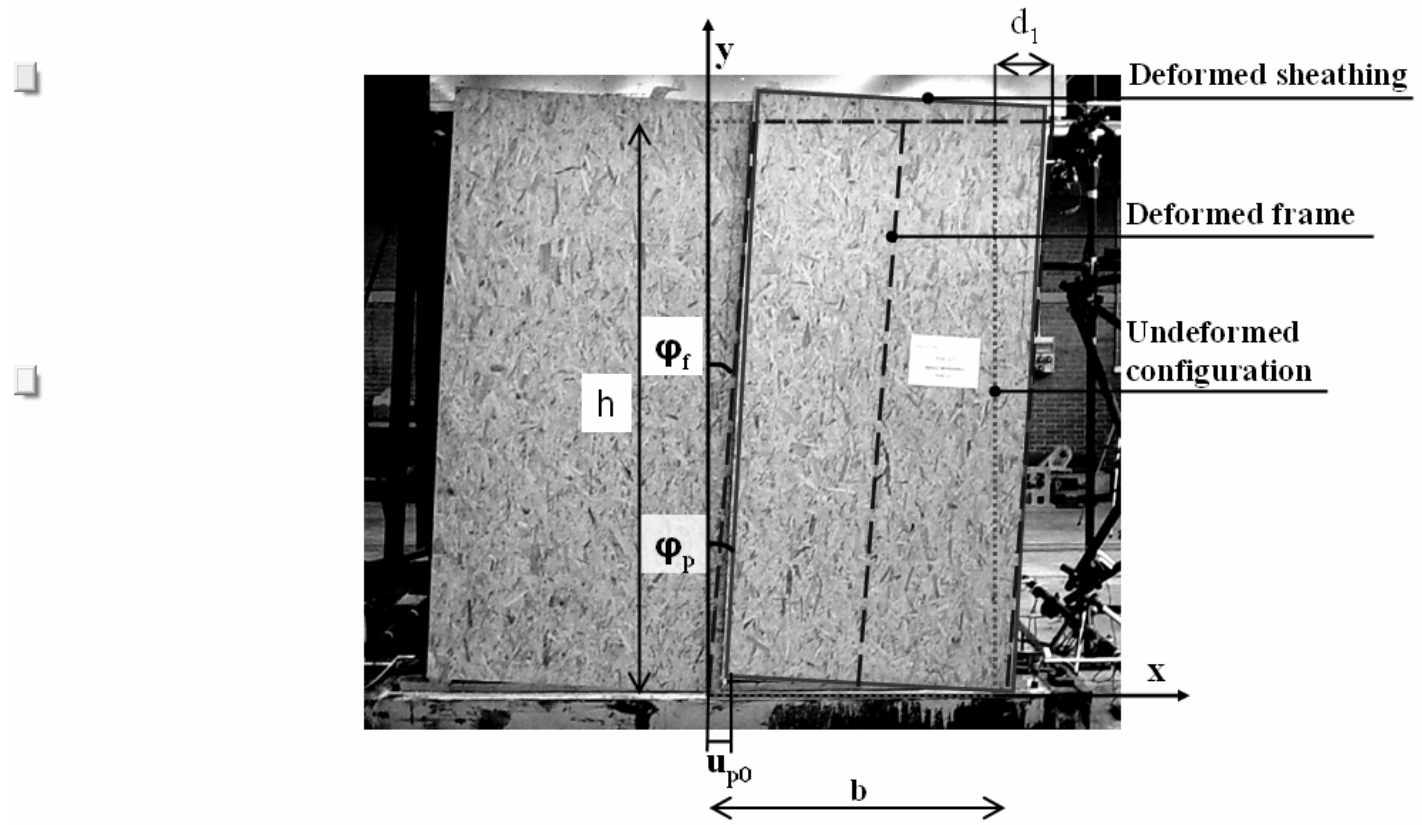

Figure 8. Full Scale Specimen and Assumed Deformation of a Shear Wall Specimen 
From equilibrium considerations, involving moment and horizontal force equilibrium for the panel and horizontal force equilibrium for the top track, and assuming that the load-deflection curve of sheathing-to-frame connections is linear, the following relationships can be obtained:

$\varphi_{f}=\frac{2 h\left[K_{x} \cdot I_{x}-\left(S_{x}\right)^{2}-\frac{b \cdot K_{x} \cdot S_{y}}{2}+K_{x} \cdot I_{y}\right] H}{\left(S_{x, m} \cdot S_{x}-I_{x, m} \cdot K_{x}+S_{e} \cdot S_{x}-I_{e} \cdot K_{x}\right)\left(2 I_{x}-b \cdot S_{y}\right)}$

$\varphi_{f}=\frac{-2 h\left[K_{x} \cdot I_{x}-\left(S_{x}\right)^{2}\right] H}{\left[\left(I_{x, m}+I_{e}\right) K_{x}-\left(S_{x, m}+S_{e}\right) S_{x}\right]\left(2 I_{x}-b \cdot S_{y}\right)}$

$u_{p 0}=\frac{h \cdot S_{x} \cdot H}{\left[I_{x, m}+I_{e}\right] K_{x}-\left[S_{x, m}+S_{e}\right] S_{x}}$

where:

$$
\begin{array}{lcc}
K_{x}=\sum_{i=1}^{n} k_{x, i} & S_{x}=\sum_{i=1}^{n} k_{x, i} \cdot y_{i} & I_{x}=\sum_{i=1}^{n} k_{x, i}\left(y_{i}\right)^{2} \\
S_{y}=\sum_{i=1}^{n} k_{y, i} \cdot x_{i} & I_{y}=\sum_{i=1}^{n} k_{y, i}\left(x_{i}\right)^{2} & S_{x, m}=\sum_{i=1}^{m} k_{x, i} \cdot y_{i} \\
K_{e}=k_{x e} \cdot n_{e} & S_{e}=k_{x e} \cdot n_{e} \cdot h & I_{e}=k_{x e} \cdot n_{e} \cdot h^{2}
\end{array}
$$

in which $\varphi_{f}$ and $\varphi_{p}$ are the rotations (defined positive as anticlockwise rotations) of the frame and sheathing panel, respectively; $u_{p 0}$ is the translation of the sheathing panel along the X direction; $k_{x, i}$ and $k_{y i}$ represent the stiffness of sheathing-to-frame connections for displacements along the $\mathrm{X}$ and $\mathrm{Y}$ directions, respectively; $k_{x e}$ is the stiffness of sheathing fasteners connecting the sheathing panel to the top track for displacement along the $\mathrm{X}$ direction; $x_{i}$ and $y_{i}$ are the connection coordinates along the $\mathrm{X}$ and $\mathrm{Y}$ directions; $i$ is the generic sheathing-to-frame connection, $n$ is the total number of sheathing-to-frame connections; $m$ is the number of fasteners connecting the sheathing panel to studs; $n_{e}$ is the number of fasteners connecting the sheathing panel to the top track; $H$ is the horizontal external force per unit length. When for sheathing fasteners a linear load-displacement response is assumed ( $k_{x, i}, k_{y, i}$, and $k_{x e}$ are constant values), Eq. 12 gives a closed-form solution and the top wall displacement $\left(d_{f}\right)$ can be evaluated as follows:

$$
d_{f}=\varphi_{f} h
$$

where $\varphi_{f}$ is calculated through Eq. 12. When a nonlinear load-displacement curve is adopted for sheathing fasteners, Eq. 12 through 15 can be written in differential format and can be used in a numerical step-by-step procedure which allows the load $(H)$ vs. deflection $\left(d_{f}\right)$ response curve of the wall to be obtained. More details about the numerical procedure are given in Fiorino et al. [20]. The lateral displacement due to the shear deformation of the sheathing panels $\left(d_{s}\right)$ is obtained by adopting the equation for shear deformation of a thin, edge-loaded, plate:

$$
d_{s}=\frac{H \cdot h}{G \cdot t_{p} \cdot b}
$$


where: $G$ is the shear modulus of elasticity of the panel material; $b$ is the width of the sheathing panel; $t_{p}$ is the panel thickness.

The bending displacement $\left(d_{b}\right)$ may be evaluated by considering the wall as a cantilever having a cross-section made of the only end studs:

$d_{b}=\frac{2 H \cdot h^{3}}{3 E \cdot A \cdot l^{2}}$

where: $E$ is the Young's modulus of steel; $A$ is the gross cross-sectional area of an end stud.

The lateral displacement due to overturning $\left(d_{a}\right)$ is calculated from the following equation:

$d_{a}=\frac{H \cdot h^{2}}{l^{2} \cdot K_{a}}$

where $K_{a}$ is the axial stiffness of the hold-down device, which can be obtained from hold-down manufacturers. Typical values of stiffness $K_{a}$ have been obtained by considering the Simpson metal-to-metal connectors (Simpson Strong-Tie Company [21]) ranging from 27 to $31 \mathrm{kN} / \mathrm{mm}$ for S/HD hold-down connectors.

\section{APPLICATION OF NOMOGRAPHS: A CASE STUDY}

The house presented hereafter shows the architectural and technological possibility of a stick built construction and, mainly, it has been designed in order to study the applicability of the presented nomographs. The architecture has been designed without having in mind any specific location or particular inhabitant requirements. It aims to be a prototype of a contemporary housing in which flexibility, environmental comfort and high structural performance are the keywords.

The dwelling develops in two floors and is organized in wide and regular spaces where the walls are distributed along the perimeter and in the center of house, in order to assure the maximum flexibility of the internal spaces (Figure 9).

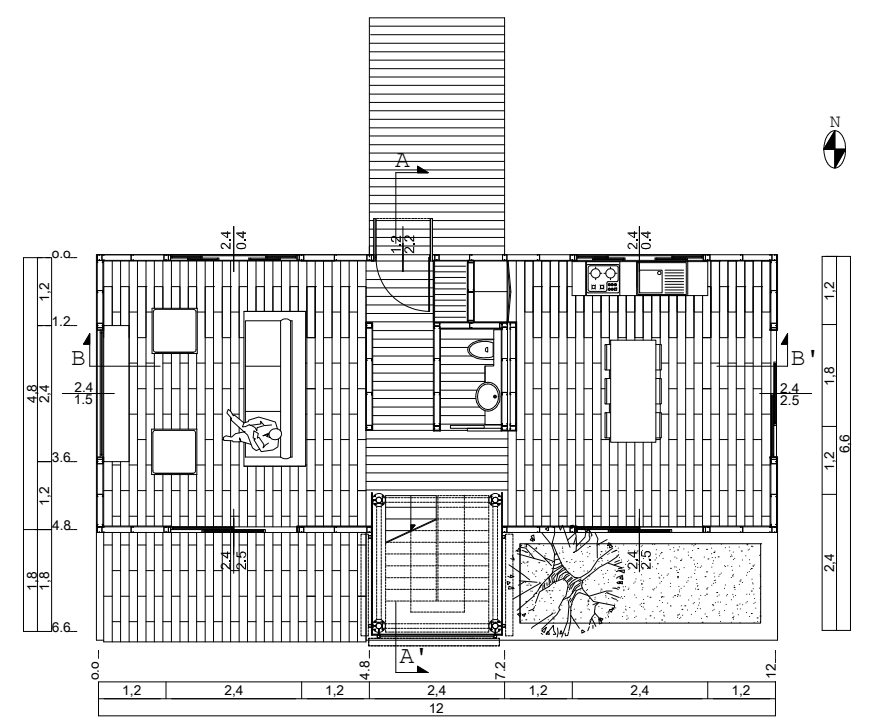

Figure 9. Case Study: Ground Floor 
The opening distribution follows environment requirements, introducing thin openings on the Nord front and wide and adequately shielded openings on the South and South-West elevations (Figure $10)$.
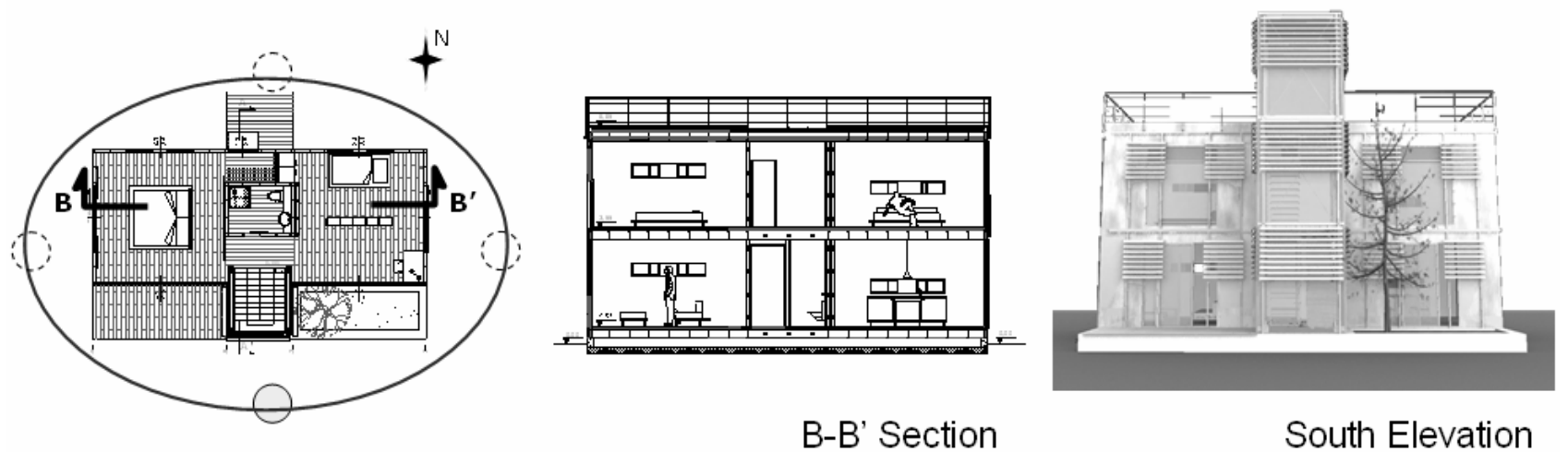

Figure 10. Case Study: Opening Distribution

The construction arises on a concrete slab, on which the steel frame is anchored by clip angles and post installed anchors. The basic framing system is characterized by discontinued walls, interrupted at each floor level by floor framing. The floor framing is composed by joists, horizontal bearing members, spaced at $600 \mathrm{~mm}$ and aligned with vertical load bearing framing members. Joists are connected at each end by a floor track: an horizontal member used as band or rim joists for flooring systems. Web stiffeners are installed at each joist bearing location to strengthen the member against web crippling and to assure the continuity of vertical bearing members (Figure 11).

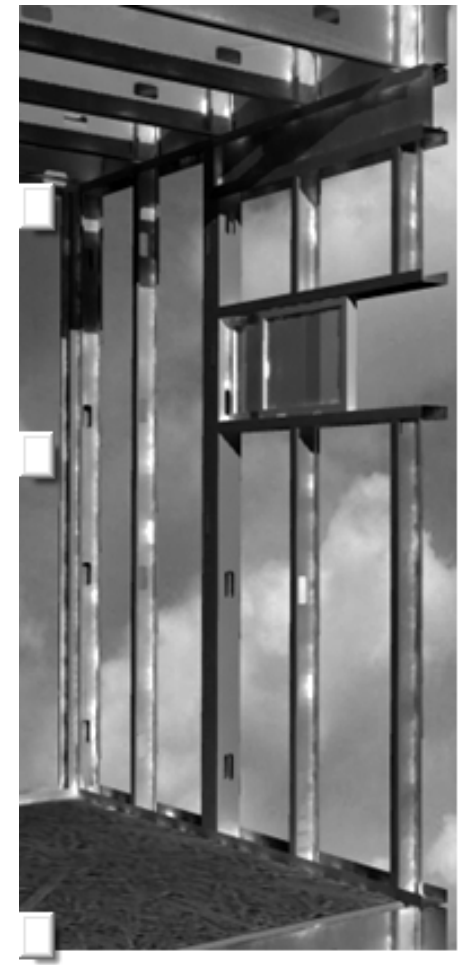

b) Wall framing

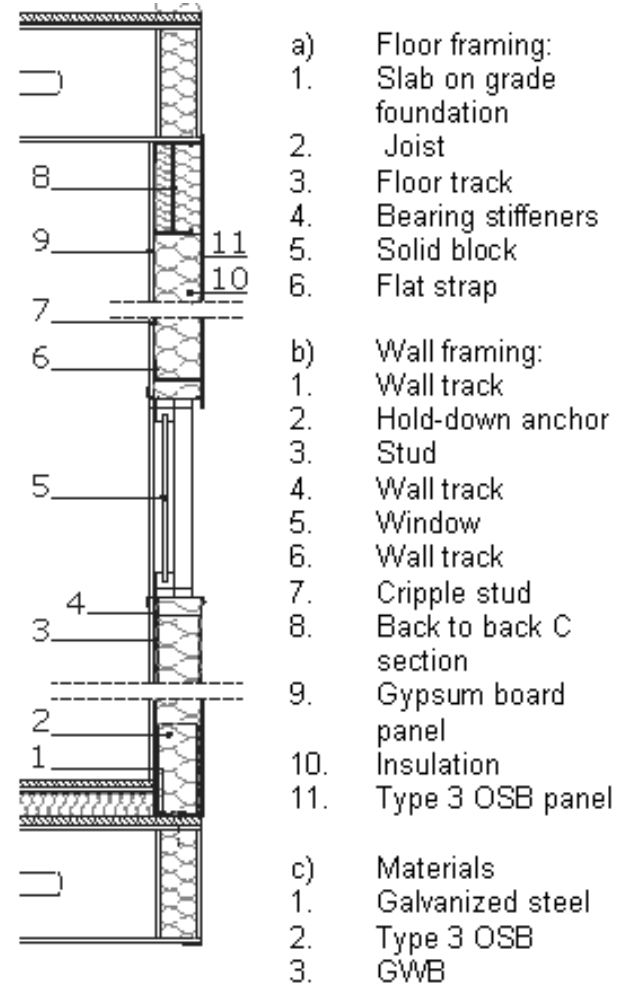

GWB

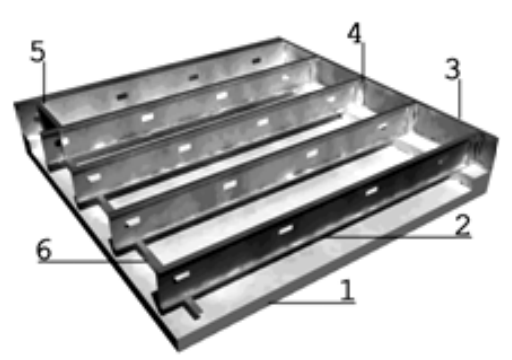

a) Floor framing

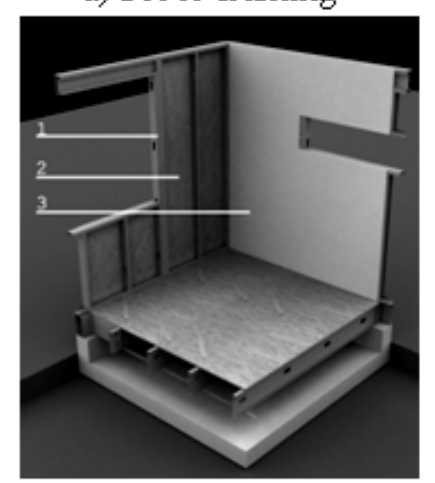

c) Materials

Figure 11. Case Study: Components and Materials

Hence, the walls have been designed following the proposed procedure.

As first step, according to the proposed design process (phase 1), the following "assigned" design parameters have been adopted: 
- $\quad 2700 \mathrm{~mm}$ high $(h)$ and $1200 \mathrm{~mm}$ long $(l)$ wall with stud spaced $(c)$ at $600 \mathrm{~mm}$;

- $\quad 9.0 \mathrm{~mm}$ thick Type 3 OSB external panels and $12.5 \mathrm{~mm}$ thick standard GWB internal panels, both having vertical orientation;

- $\quad 4.2 \times 25 \mathrm{~mm}($ diameter $\times$ length) flat head self-drilling screw sheathing fasteners having interior spacing $(p)$ of $300 \mathrm{~mm}$ and edge distance $(e)$ of $10 \mathrm{~mm}$;

- studs having $100 \times 50 \times 10 \mathrm{~mm}$ (outside-to-outside web depth $\times$ outside-to-outside flange size $\times$ outside-to-outside lip size) lipped channel section, and track having $100 \times 40 \times 1.00 \mathrm{~mm}$ (outside-to-outside web depth $\times$ outside-to-outside flange size $\times$ thickness) unlipped channel section, both fabricated from $\mathrm{S} 350 \mathrm{GD}+\mathrm{Z}$ hot dipped galvanized zinc coated steel grade;

- S/HD10B metal-to-metal connectors by Simpson Strong-Tie Company (Simpson Strong-Tie Company [21]) and HIT-RE 500 with HIS-N 8.8 adhesive-bonded anchors by HILTI (Hilti [22]) hold-down devices;

- $\quad$ HST M8 mechanical shear anchors by HILTI (Hilti [22]).

The evaluation of the sheathing fasteners exterior spacing (phase 2) performed with nomographs for LD and NS seismic analysis are shown in Figures 12 and 13, respectively. In particular, in the "LD" nomograph both strength $\left(\bar{H}_{C}\right)$ and action $\left(\bar{H}_{D}\right)$ are expressed for wall unit length and have been normalised respect to the seismic weight $(w)$. In the "NS" nomograph the "strength" $\left(\bar{H}_{C} \cdot g / w\right)$ and "action" $\left(S_{a}\right)$ parameters have been normalised respect to the gravity acceleration $\left(\bar{H}_{C} / w, S_{a} / g=\bar{H}_{D} / w\right)$.

The functions $f_{K}, f_{H}, f_{y}$, and $f_{u}$ used in these nomographs have been obtained by applying the model proposed in Section 3 starting from force - displacement (slip) sheathing fastener response curve derived on the basis of experimental tests carried out by the authors on typical screw connections for cold-formed steel housing (Fiorino et al. [23]).

The elastic acceleration demand spectra provided by Eurocode 8 (CEN [24]) and adopted also by the new Italian Seismic Code (OPCM [25]) have been assumed as spectral acceleration functions $\left(f_{\text {SaT }}, f_{\text {Sad }}\right)$. In particular, the Italian Seismic Code defines soil types A, B, C, D, and E according to the Eurocode 8 classification, but only three spectra are adopted, by grouping the soil types B, C and $\mathrm{E}$ under one spectrum type ("BCE"). Values of the peak design ground acceleration $\left(a_{g}\right)$ on type A soil (for earthquakes having 10\% chance of being exceeded over 50 years - average return period 474 years) equal to $0.35 \mathrm{~g}, 0.25 \mathrm{~g}$, and $0.15 \mathrm{~g}$ (for seismic zones having low, medium and high intensity, respectively) have been assumed. In addition, the spectra adopted for the LD procedure have been obtained by assuming a strength reduction factor $q=4.0$ (Boudreault et al. [26]). A viscous damping ratio $\xi=5 \%$ has been adopted in all cases, in accordance with literature data (Dubina et al. [27], The Committee on Light-gauge Steel Structures [28]).

In Figure 12, the LD seismic analysis is performed for the presented case study, which is characterized by a seismic weight equal to $w=20 \mathrm{kN} / \mathrm{m}$. Moreover, a peak design ground acceleration equal to $a_{g}=0.35 g$ and soil type "B" have been considered. By assuming as attempt an exterior spacing $s=150 \mathrm{~mm}$, for a seismic weight $w=20 \mathrm{kN} / \mathrm{m}$, the point A on the top left graph identifies the normalised strength $\left(\bar{H}_{C} / w=0.40\right)$, while the point $\mathrm{B}$ on the bottom left graph defines the stiffness $(\bar{K}=0.95 \mathrm{kN} / \mathrm{mm} \cdot \mathrm{m})$. The point $\mathrm{C}$ (defining a structural period $T=0.292 \mathrm{~s}$ ) is obtained on the bottom right graph by the intersection of the horizontal line drawn from point $\mathrm{B}$ and the curve relevant to $w=20 \mathrm{kN} / \mathrm{m}$. Finally, on the top right graph the intersection of the vertical line drawn from point $\mathrm{C}$ and the curve relevant to $a_{g}=0.35 g$ and "B" soil type defines the normalised actions $\left(\bar{H}_{D} / w=0.27\right.$, point D). Since acting seismic force is less than seismic resistance (point $\mathrm{D}$ is lower than point $\mathrm{A})$, then the assumed exterior spacing $(s=150 \mathrm{~mm})$ is adequate $\left(\bar{H}_{D} / \bar{H}_{C}=0.68\right)$. 
Hence, a NS seismic analysis has been performed (Figure 13). In this case, starting from $s=150 \mathrm{~mm}$ and $w=20 \mathrm{kN} / \mathrm{m}$ the point $\mathrm{A}$ on the top left graph defines the normalised strength $\left(\bar{H}_{C} / w=0.40\right)$, while the points $\mathrm{B}$ and $\mathrm{C}$ on the bottom right graph identify the yield displacement $\left(d_{y}=9 \mathrm{~mm}\right)$ and ultimate displacement $\left(d_{u}=d_{C}=52 \mathrm{~mm}\right)$. Therefore, the capacity spectrum (broken line O-Y-U) is obtained on the top right graph by the intersection of the horizontal line drawn from point $A$ and vertical lines drawn from points B and C. Finally, by considering on the top right graph the relevant demand spectrum ( $a_{g}=0.35 g$ and "B" soil type), the well known capacity-demand-diagram method (ATC-40 [29]) can be used to find the displacement demand $\left(d_{D}=34 \mathrm{~mm}\right.$, point D). The NS procedure confirms that the assumed exterior spacing is adequate $\left(d_{D} / d_{C}=0.65\right)$.

The last step of the proposed design process (phase 3) is performed through the "OC" nomograph (Figure 14). This nomograph shows the design resistance of sheathing fasteners $\left(\bar{H}_{C, f, d}\right)$ together with the characteristics resistances of studs, hold-down anchors and shear anchors reduced by considering the relevant overstrength factors $\left(\bar{H}_{C, s, k} / \gamma_{o v, s}, \bar{H}_{C, h a, k} / \gamma_{o v, h a}, \bar{H}_{C, s a, k} / \gamma_{o v, s a}\right)$. In particular, by assuming: $\gamma_{o v, s}=2.0, \gamma_{o v, h a}=4.0, \gamma_{o v, s a}=3.0$, and $\bar{H}_{C, s, k} / \bar{H}_{C, s, d}=1.0$, $\bar{H}_{C, h a, k} / \bar{H}_{C, h a, d}=2.0, \bar{H}_{C, s a, k} / \bar{H}_{C, s a, d}=1.5$, and $\bar{H}_{C, f, a v} / \bar{H}_{C, f, d}=2.0$, different values of $\bar{H}_{C, s, k} / \gamma_{o v, s}, \bar{H}_{C, h a, k} / \gamma_{o v, h a}, \bar{H}_{C, s a, k} / \gamma_{o v, s a}$ have been calculated by varying the wall component design parameters $t, a$, and $\phi$, respectively. In this way the "capacity design" criteria (see Eq. 10) can be applied for the selection of more convenient values of such parameters. In the examined case study this means to draw a vertical line corresponding to the selected exterior spacing $s=$ $150 \mathrm{~mm}$ on the "OC" nomograph and then to identify the point corresponding to the resistance of sheathing fasteners (point $\mathrm{A}, \bar{H}_{C, f, d}=12 \mathrm{kN} / \mathrm{m}$ ). The definition of $t, a$, and $\phi$ is then performed by identifying, for each component, the relevant line which is immediately higher than the point $\mathrm{A}$ $(t=1.0 \mathrm{~mm}$, point $\mathrm{L} ; a=300 \mathrm{~mm}$, point $\mathrm{G}, \phi=10 \mathrm{~mm}$, point $\mathrm{H})$.

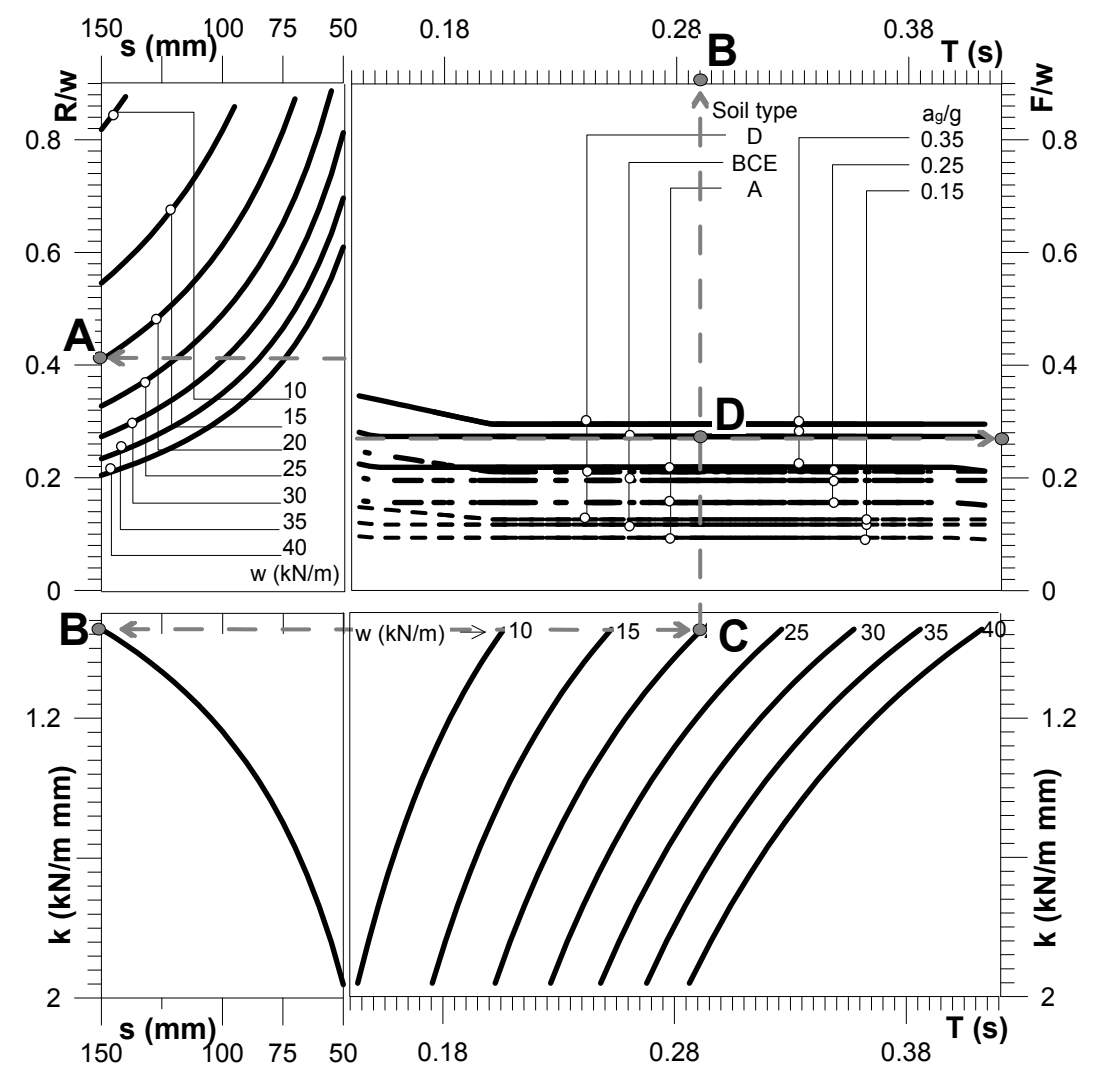

Figure 12. Application of “LD” Nomograph 


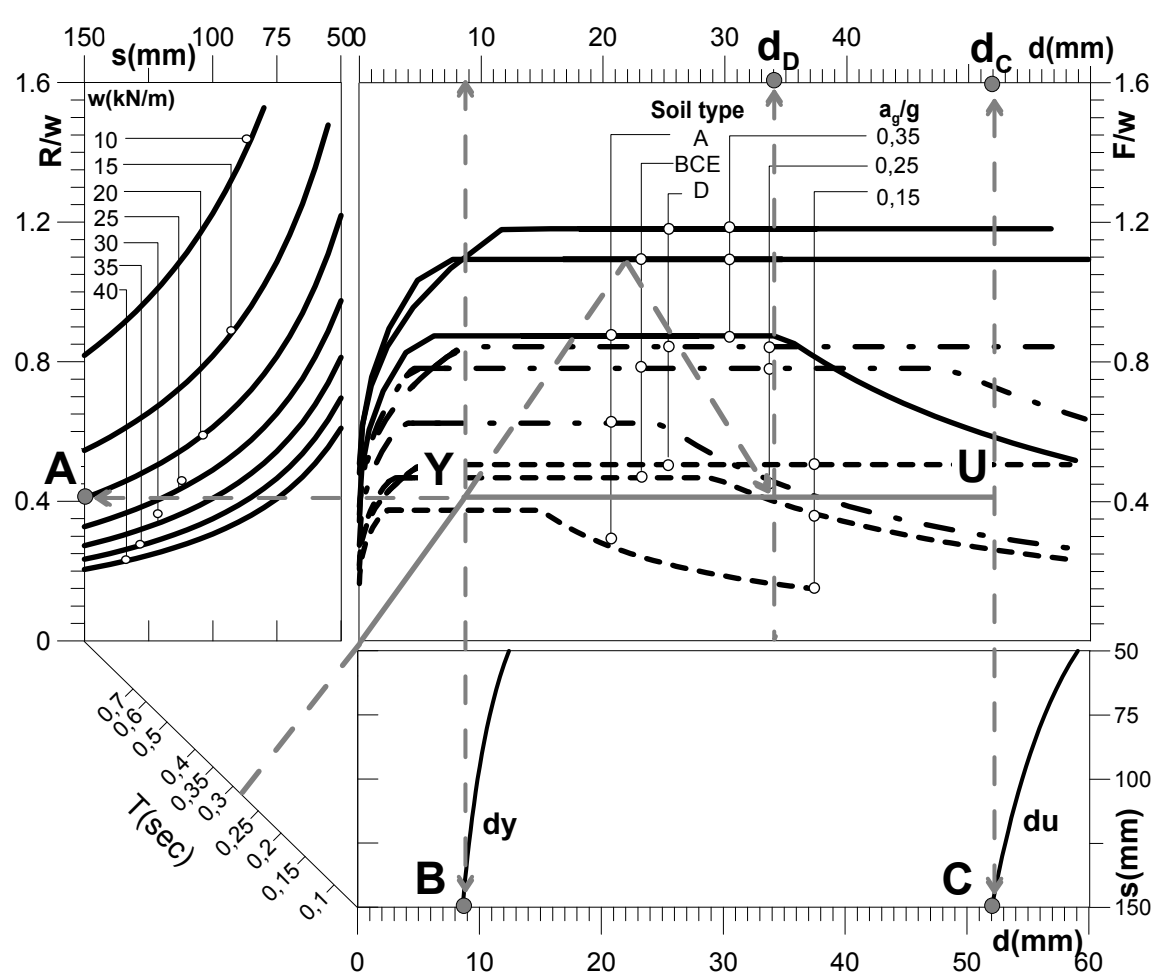

Figure 13. Application of "NS" Nomograph

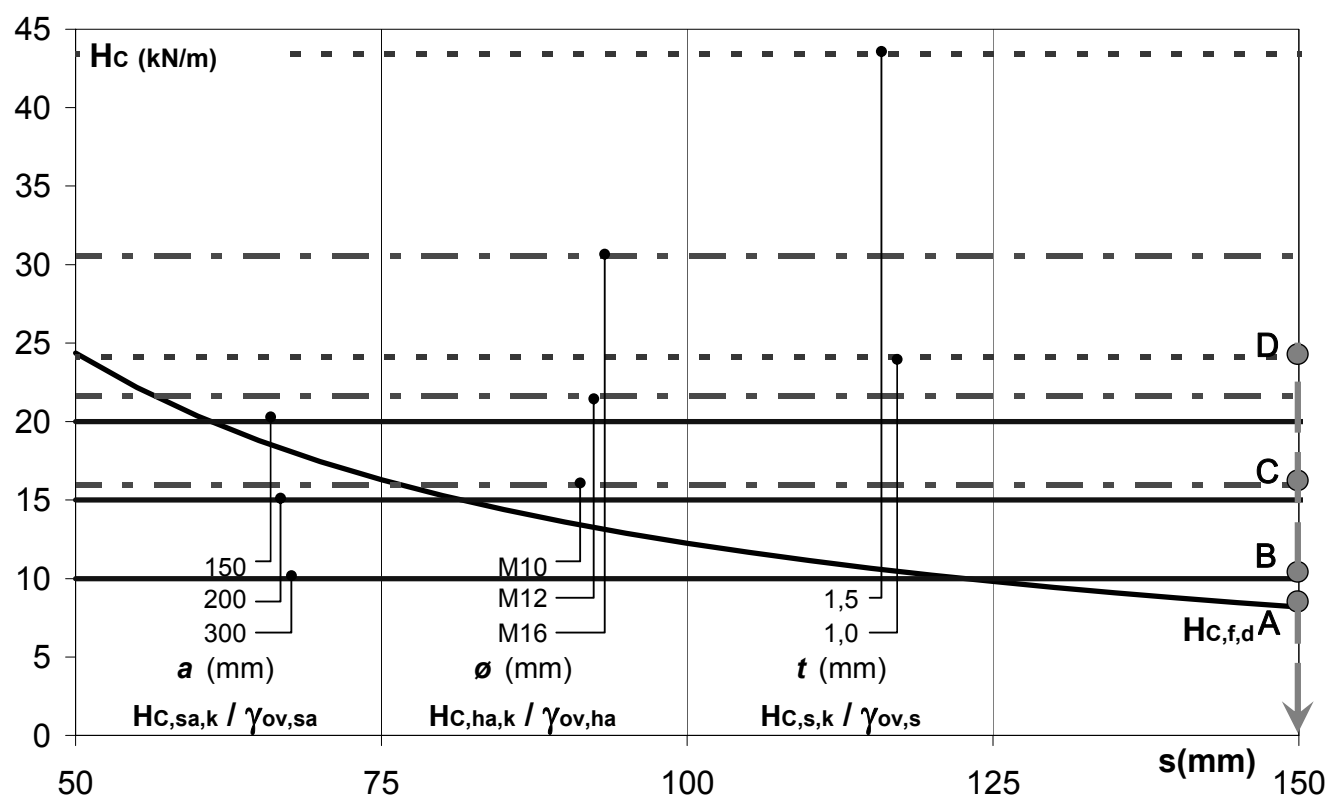

Figure 14: Application of "OC" Nomograph

\section{CONCLUSIONS}

This paper presents a design procedure for cold formed steel housing in seismic area. It is based on the recognized assumption that the shear walls are the main resistant building components and that the best behaviour of a CFS housing can be reached when the collapse under seismic loads is due to the sheathing-to-stud screw failure. Hence, the proposed design procedure, after the definition of the shear wall geometry and technological components, allows the screw sheathing-to-stud fasteners spacing to be defined through a linear dynamic (LD nomograph) analysis or a nonlinear static (NS nomograph) analysis. Finally, the complete definition of all the other wall structural 
components (studs, shear and hold down anchors) is performed in accordance with "capacity design criteria" (OC nomograph). Moreover, the analytical model used to define the wall strength curves is presented. Finally the procedure applicability is investigated through the design of a two-story CFS dwelling.

\section{REFERENCES}

[1] Gad, E. F., Chandler, A. M., Duffield, C. F., and Stark, G., "Lateral Behaviour of Plasterboard-Clad Residential Steel Frames.” J. Struct. Eng., 1999, Vol. 125, pp. 32-39.

[2] Tian, Y.S., Wang, J. and Lu, T.J. "Racking Strength and Stiffness of Cold-formed Steel Wall Frames", Journal of Constructional Steel Research, 2004, Vol. 60, pp. 1069-1093.

[3] Branston, A.E., Chen, C.Y., Boudreault, F.A. and Rogers, C.A., "Testing of Light-gauge Steel-frame - Wood Structural Panel Shear Walls," Can. J. Civ. Eng., 2006, Vol. 33, pp. 561-572.

[4] Fülöp, L.A. and Dubina, D., "Design Criteria for Seam and Sheeting-to-Framing Connections of Cold-Formed Steel Shear Panels", Journal of Structural Engineering, ASCE, 2006, Vol.132, No.4, pp. 582-590.

[5] Landolfo, R., Fiorino, L. and Della Corte, G., "Seismic Behaviour of Sheathed Cold-formed Structures: Physical Tests," Journal of Structural Engineering, ASCE, 2006, Vol. 132, No.4, pp 570-581.

[6] Langea, J. and Naujoksb, B. "Behaviour of Cold-formed Steel Shear Walls Under Horizontal and Vertical Loads", Thin-Walled Structures, 2006, Vol. 44, pp. 1214-1222.

[7] Serrette, R, Nguyen, H. and Hall, G., "Shear Wall Values for Light Weight Steel Framing", Report No. LGSRG-3-96, Light Gauge Steel Research Group, Department of Civil Engineering, Santa Clara University, Santa Clara, 1996.

[8] Uniform Building Code, "International Conference of Building Officials", Vol. 2, Whittier, CA, USA, 1997.

[9] International Building Code, "International Code Council", Inc. Falls Church, VA, USA, 2000.

[10] Fiorino, L., Iuorio, O., Landolfo, R., "Sheathed cold-formed steel housing: a seismic design procedure", Thin Walled Structures, 2009, Vol. 47, pp. 919 - 930.

[11] Serrette, R., Hall, G. and Nguyen, H., "Dynamic Performance of Light Gauge Steel Framed Shear Walls", Proceedings of 13th International Specialty Conference on Cold-formed Steel Structures, St. Louis, 1996, pp. 487-498.

[12] Dolan, J.D., "The Dynamic Response of Timber Shear Walls", PhD thesis, University of British Columbia, Vancouver, 1989.

[13] Dolan, J.D. and Foschi, R.O., "Structural Analysis Model for Static Loads on Timber Shear Walls", Journal of Structural Engineering, 1991, Vol. 117, No. 3, pp. 851-861.

[14] White, M.W. and Dolan, J.D., "Nonlinear Shear-Wall Analysis", Journal of Structural Engineering, 1995, Vol. 121, No. 11, pp. 1629-1635.

[15] Easley, J.T., Foomani, M. and Dodds, R.H., "Formulas for Wood Shear Walls", Journal of Structural Division, 1982, Vol. 105, pp. 2460-2478.

[16] McCutchenon, W.J., "Racking Deformation in Wood Shear Walls", Journal of Structural Engineering, ASCE, 1985, Vol. 111, pp. 257-269.

[17] Kaellsner, B. and Lam, F., "Diaphragms and Shear Walls". In STEP Lectures: Holzbauwerke nach Eurocode 5-Grundlagen, Entwicklungen, Ergaenzungen, Fachverlag Holz, Duesseldorf, Germany: 15/1-15/19, 1995.

[18] Hieta, J. and Kesti, J., "Design Recommendations for Shear Walls Braced with Sheathings", Teräsrakenteiden tutkimus- ja kehityspäivät 13.-14.6.2002, Mikkeeli, Finnish Constructional Steelwork association, 2002. 
[19] Richard, R.M. and Abbott, B.J., "Versatile Elastic-plastic Stress-strain Formula", Journal of Mechanical Engineering, 1975, Vol. 101, No. 4, pp. 511-515.

[20] Fiorino, L., Della Corte, G. and Landolfo, R., "Lateral Response of Sheathed Cold-Formed Shear Walls: An Analytical Approach", Proceedings of 18th International Specialty Conference on Cold-Formed Steel Structures, Orlando, 2006.

[21] Simpson Strong-Tie Company, http://www.strongtie.com, 2007.

[22] Hilti North America product technical guide, 2005.

[23] Fiorino, L., Della Corte, G. and Landolfo, R., "Experimental Tests on Typical Screw Connections for Cold-formed Steel Housing", Engineering Structures, Elsevier, 2007, Vol. 29, No. 8, pp.1761-1773.

[24] EN 1998-1 - Eurocode 8 "Design of Structures for Earthquake Resistance - Part 1: General Rules, Seismic Actions and Rules for Buildings", European Committee for Standardization (CEN), Bruxelles, 2005.

[25] OPCM 3431/2005. "Primi Elementi in Materia di criteri Generali per la Classificazione Sismica del Territorio Nazionale e di Normative Tecniche per le Costruzioni in Zona Sismica", Ordinanza della Presidenza del Consiglio dei Ministri No.3431/2005, Rome, 2005.

[26] Boudreault, F.A., Blais, C. and Rogers, C.A., "Seismic Force Modification Factors for Light-gauge Steel-frame - Wood Structural Panel Shear Walls", Canadian Journal of Civil Engineering, 2007, Vol. 34, pp. 56-65.

[27] Dubina, D., Fülöp, L.A., Aldea, A., Demetriu, S. and Nagy, Zs., "Seismic Performance of Cold-formed Steel Framed Houses", Proceedings of 5th International Conf. on Behaviour of Steel Structures in Seismic Areas (STESSA), Yolkohama, 2006, pp 429-435.

[28] The Committee on Light-gauge Steel Structures, The Japan Iron and Steel Federation, Steel-Framed House Association. "Steel-framed Houses - High Structural Performances and Habitability, Steel Construction Today \& Tomorrow", 2004, Vol. 10, pp. 1-9.

[29] ATC 40 "Seismic Evaluation and Retrofit of Concrete Buildings", Applied Technology Council (ATC), Redwood City, 1996. 